\title{
Carbon-Cycle Feedbacks Operating in the Climate System
}

\author{
Richard G. Williams ${ }^{1}$ (D) - Anna Katavouta ${ }^{1}$ (D) . Philip Goodwin ${ }^{2}$ (I)
}

Published online: 22 November 2019

(C) The Author(s) 2019

\begin{abstract}
Climate change involves a direct response of the climate system to forcing which is amplified or damped by feedbacks operating in the climate system. Carbon-cycle feedbacks alter the land and ocean carbon inventories and so act to reduce or enhance the increase in atmospheric $\mathrm{CO}_{2}$ from carbon emissions. The prevailing framework for carbon-cycle feedbacks connect changes in land and ocean carbon inventories with a linear sum of dependencies on atmospheric $\mathrm{CO}_{2}$ and surface temperature. Carbon-cycle responses and feedbacks provide competing contributions: the dominant effect is that increasing atmospheric $\mathrm{CO}_{2}$ acts to enhance the land and ocean carbon stores, so providing a negative response and feedback to the original increase in atmospheric $\mathrm{CO}_{2}$, while rising surface temperature acts to reduce the land and ocean carbon stores, so providing a weaker positive feedback for atmospheric $\mathrm{CO}_{2}$. The carbon response and feedback of the land and ocean system may be expressed in terms of a combined carbon response and feedback parameter, $\lambda_{\text {carbon }}$ in units of $\mathrm{W} \mathrm{m}^{-2} \mathrm{~K}^{-1}$, and is linearly related to the physical climate feedback parameter, $\lambda_{\text {climate }}$, revealing how carbon and climate responses and feedbacks are inter-connected. The magnitude and uncertainties in the carbon-cycle response and feedback parameter are comparable with the magnitude and uncertainties in the climate feedback parameter from clouds. Further mechanistic insight needs to be gained into how the carbon-cycle feedbacks are controlled for the land and ocean, particularly to separate often competing effects from changes in atmospheric $\mathrm{CO}_{2}$ and climate forcing.
\end{abstract}

Keywords Carbon cycle · Carbon emissions · Carbon feedbacks $\cdot$ Climate feedbacks

\section{Introduction}

Predicting our future climate is difficult due to feedbacks operating in the climate system [1], acting to amplify or damp the effect of climate forcing. To understand what a feedback is, consider the following every-day example: when a pan of water is heated on a stove, there is a direct warming response of the water from the heat supplied. At the same time, the pan is cooled by infrared radiation and this loss of heat is inhibited by the evaporation increasing the water vapour above the pan. Hence, the increase in the

This article is part of the Topical Collection on Carbon Cycle and Climate

Richard G. Williams

ric@liverpool.ac.uk

1 Department of Earth, Ocean and Ecological Sciences, School of Environmental Sciences, University of Liverpool, Liverpool, UK

2 School of Ocean and Earth Sciences, National Oceanography Centre, University of Southampton, Southampton, UK water vapour is providing a positive feedback that reinforces the initial supply of heat and leads to greater warming [2]. There is a wide range of positive and negative responses and feedbacks operating in the climate system, such as involving radiative responses from changes in water vapour, clouds and surface albedo [3-7]; for a discussion of external forcing, climate response and feedbacks, see [8] and for reviews of linear models for climate feedbacks, see [9].

The present-day climate system is being forced by carbon emissions [10], increasing atmospheric $\mathrm{CO}_{2}$ and surface temperature (Fig. 1a, blue and red arrows). The increase in the atmospheric carbon inventory is less than the cumulative carbon emission due to carbon being sequestered by the land and ocean systems. These changes in the land and ocean carbon inventories may be expressed in terms of a carbon-cycle framework with carbon-cycle parameters measuring the dependencies of the land and ocean carbon inventories on atmospheric $\mathrm{CO}_{2}$ and surface temperature [11-14] (Fig. 1a, black arrows).

The carbon uptake by the land and ocean after an increase in atmospheric $\mathrm{CO}_{2}$ may be viewed in terms of a combination of transient responses and feedbacks. The 
(a) schematic view

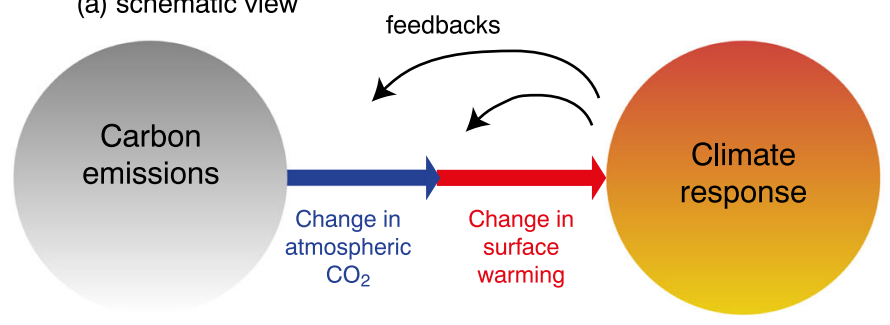

(b) cumulative land carbon uptake

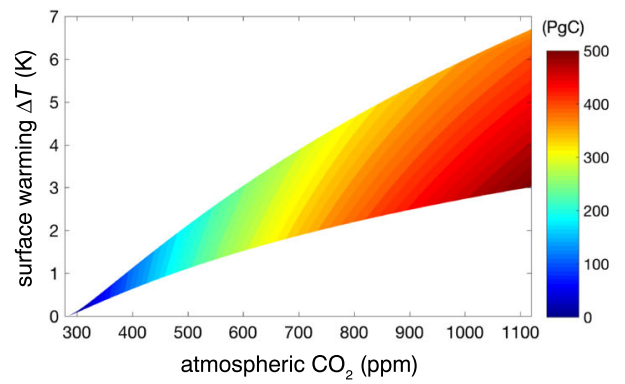

Fig. 1 (a) Schematic view of how carbon emissions drive a climate response by increasing atmospheric $\mathrm{CO}_{2}$ and driving surface warming (blue and red arrows respectively). The climate response is modified by feedbacks (black arrows) enhancing the effects of the changes in the atmospheric $\mathrm{CO}_{2}$ and surface temperature. An illustrative view of how cumulative carbon uptake ( $\mathrm{PgC}$, colours) for (b) the land and (c) the (c) cumulative ocean carbon uptake

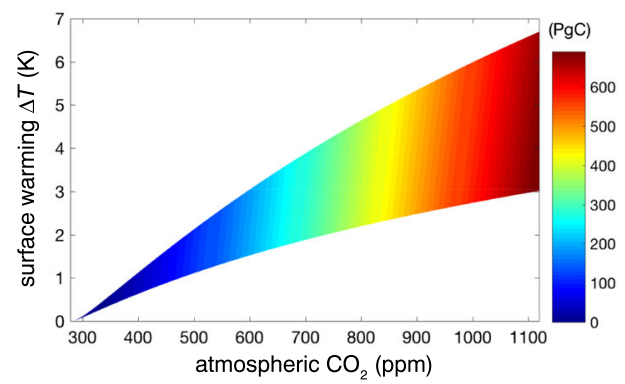

ocean depends upon increases in atmospheric $\mathrm{CO}_{2}(\mathrm{ppm})$ versus the increase in surface temperature, $\Delta T(\mathrm{~K})$, which is generated from 100 simulations of an efficient WASP Earth system model [19] forced by an imposed $1 \%$ annual rise in atmospheric $\mathrm{CO}_{2}$ under multiple warming responses with different cloud feedback parameters for 140 years until $4 \times \mathrm{CO}_{2}$ is reached

emissions being subsequently taken up by the ocean and so acts as a positive feedback for atmospheric $\mathrm{CO}_{2}$;

3. Increased surface warming may also enhance plant and soil respiration, so acting to increase atmospheric $\mathrm{CO}_{2}$ and provides a positive feedback;

4. If there is surface warming of the ocean, the ventilation of the ocean decreases and so the ocean uptake of carbon decreases and instead atmospheric $\mathrm{CO}_{2}$ increases, which enhances radiative forcing and provides a positive feedback that reinforces the initial perturbation.

Our aim is to review how carbon-cycle responses and feedbacks are represented [11-14], providing guidance as to the underlying mechanisms and emphasize how the carbon responses and feedbacks may be combined together in terms of a carbon-cycle response and feedback parameter [13], directly analogous to how physical climate feedbacks are represented [7]. For carbon-cycle responses and feedbacks, we know that there are large inter-model differences in the magnitude of these feedbacks [13-15], but we do not understand how these responses and feedbacks evolve in time with changes in the state of the climate system and the carbon forcing being experienced. We need to solve this problem if we are to understand how our future climate is going to evolve and identify how much carbon may be emitted before reaching future warming targets. 


\section{Carbon-Cycle Feedbacks and Changes in Carbon Inventories}

Cumulative carbon emissions, $\Delta C_{\mathrm{em}}$, drive an increase in the combined carbon inventories for the atmosphere, land and ocean [16],

$\Delta C_{\mathrm{em}}=\Delta C_{\mathrm{atmos}}+\Delta C_{\mathrm{land}}+\Delta C_{\mathrm{ocean}}$,

where $\Delta C_{\text {atmos }}, \Delta C_{\text {land }}$ and $\Delta C_{\text {ocean }}$ represent the respective changes in the atmospheric, land and ocean inventories since the pre-industrial era and these carbon inventories changes are evaluated in $\mathrm{PgC}$; the change in atmospheric carbon inventory, $C_{\text {atmos }}$, is dominated by the contribution from atmospheric $\mathrm{CO}_{2}$.

The land and ocean carbon inventories may be viewed as being dependent on the carbon state of the climate system [15], such that

$C_{\text {land }}+C_{\text {ocean }}=F$ (climate state variables $)$,

where $F$ is a function defining the climate system and the climate-state variables may span a wide set of physical and biogeochemical variables. These climate-state variables would ideally be independent of each other within the climate function, but defining variables independent of each other is difficult to achieve due to the inter-connection of processes in the climate system.

The climate-state variables are usually taken to be the atmospheric carbon inventory, $C_{\text {atmos }}$, and global-mean surface air temperature, $T$, as proxies for climate change, such that

$C_{\text {land }}+C_{\text {ocean }}=F\left(C_{\text {atmos }}, T\right)$.

For the terrestrial system, climate drivers are found to scale with the change in global-mean surface temperature [17], so supporting the choice of surface temperature in Eq. 3. For the ocean, the carbon uptake may initially depend on surface temperature, as solubility decreases in warmer waters and so inhibits carbon uptake from the atmosphere; however, the longer-term ocean carbon uptake is controlled more by the carbon storage in the ocean interior and might instead depend upon depth-mean ocean temperature [18].

\section{Illustration of Land and Ocean Carbon Dependence on Atmospheric $\mathrm{CO}_{2}$ and Temperature}

The dependence of the cumulative carbon uptake of the land and ocean on atmospheric $\mathrm{CO}_{2}$ and surface temperature is illustrated using 100 simulations of an efficient Earth system model [19] (Fig. 1b, c). The model is integrated with an imposed $1 \%$ annual rise in atmospheric $\mathrm{CO}_{2}$ under multiple warming responses for 140 years until $4 \times \mathrm{CO}_{2}$ is reached. This ensemble of simulations span parameter space by including variations in the cloud climate feedback, altering the climate sensitivity from typically 2 to around $6 \mathrm{~K}$ per doubling of atmospheric $\mathrm{CO}_{2}$, although all simulations include the same representation of the terrestrial response.

Cumulative land and ocean carbon uptake increases with rising atmospheric $\mathrm{CO}_{2}$ (Fig. 1b, c), but this carbon uptake is reduced with the rising surface temperature. While the cumulative carbon uptake alters in a consistent way with increased uptake with atmospheric $\mathrm{CO}_{2}$ and decreased uptake with warming, there is a change in the curvature in this relationship in Fig. 1b, c. While the precise quantitative values for this dependence are likely to vary between climate models, the general dependencies of the carbon inventories depicted here on changes in atmospheric $\mathrm{CO}_{2}$ and surface temperature are likely to be robust.

\section{Linear Closure for Carbon-Cycle Feedbacks}

Returning to the definition of the land and ocean carbon inventories in terms of the climate system (3), changes in the land and ocean carbon inventories may be expressed as

$$
\begin{aligned}
\Delta C_{\text {land }}+\Delta C_{\text {ocean }}= & F\left(C_{\text {atmos }, 0}+\Delta C_{\text {atmos }}, T_{0}+\Delta T\right) \\
& -F\left(C_{\text {atmos }, 0}, T_{0}\right),
\end{aligned}
$$

where terms in the parentheses represent the independent variables and subscript 0 denotes the time of the preindustrial.

The function defining the carbon state of the climate system, $F$, may be expanded as a Taylor series [15], such that

$$
\begin{aligned}
\Delta C_{\text {land }}+\Delta C_{\text {ocean }}= & \left.\frac{\partial F}{\partial C_{\text {atmos }}}\right|_{0} \Delta C_{\text {atmos }}+\left.\frac{\partial F}{\partial T}\right|_{0} \Delta T \\
& +\left.\frac{\partial^{2} F}{\partial C_{\text {atmos }} \partial T}\right|_{0} \Delta C_{\text {atmos }} \Delta T \\
& +\left.\frac{1}{2} \frac{\partial^{2} F}{\partial C_{\text {atmos }}^{2}}\right|_{0} \Delta C_{\text {atmos }}^{2}+\left.\frac{1}{2} \frac{\partial^{2} F}{\partial T}\right|_{0} \\
& \times \Delta T^{2}+R_{3},
\end{aligned}
$$

where $R_{3}$ represents the effect of higher derivative terms and each differential term is formally evaluated with other variables kept constant at their pre-industrial value. Approximating by neglecting the second-order and higher derivative terms leads to a linear relationship between changes in the ocean and terrestrial carbon inventories and the changes in the climate state due to atmospheric carbon and global-mean temperature $[11,12]$,

$\Delta C_{\text {land }}+\Delta C_{\text {ocean }}=\left.\frac{\partial F}{\partial C_{\text {atmos }}}\right|_{0} \Delta C_{\text {atmos }}+\left.\frac{\partial F}{\partial T}\right|_{0} \Delta T$,

which may be written as

$\Delta C_{\text {land }}+\Delta C_{\text {ocean }}=\beta \Delta C_{\text {atmos }}+\gamma \Delta T$, 
Table 1 Carbon-cycle concentration and climate feedback terms, $\beta$ and $\gamma$, for the land and ocean from 5 CMIP5 Earth system models forced by an annual $1 \%$ increase in atmospheric $\mathrm{CO}_{2}$. Diagnostics are from years 121 to 140 with decadal variability filtered using a moving-average filter

\begin{tabular}{|c|c|c|c|c|c|c|c|}
\hline CMIP5 model & $\begin{array}{l}\beta \\
\mathrm{ND}\end{array}$ & $\begin{array}{l}\beta_{\text {land }} \\
\text { ND }\end{array}$ & $\begin{array}{l}\beta_{\text {ocean }} \\
\text { ND }\end{array}$ & $\begin{array}{l}\gamma \\
\operatorname{PgC~K}^{-1}\end{array}$ & $\begin{array}{l}\gamma_{\text {land }} \\
\mathrm{PgC} \mathrm{K}^{-1}\end{array}$ & $\begin{array}{l}\gamma_{\text {ocean }} \\
\mathrm{PgC} \mathrm{K}^{-1}\end{array}$ & Reference \\
\hline CanESM2 & 0.80 & 0.47 & 0.33 & -71.8 & -61.0 & -10.8 & {$[21]$} \\
\hline HadGEM2-ES & 1.06 & 0.67 & 0.39 & -70.9 & -53.2 & -17.7 & [22] \\
\hline IPSL-CM5A-LR & 1.21 & 0.76 & 0.45 & -73.8 & -57.6 & -16.2 & {$[23]$} \\
\hline MPI-ESM-LR & 1.16 & 0.71 & 0.45 & -100.6 & -83.0 & -17.6 & {$[24]$} \\
\hline Nor-ESM1-ME & 0.55 & 0.15 & 0.40 & -18.7 & -1.8 & -16.9 & {$[25]$} \\
\hline Mean & 0.95 & 0.55 & 0.40 & -67.1 & -51.3 & -15.8 & \\
\hline Std & 0.28 & 0.25 & 0.05 & 29.8 & 30.0 & 2.9 & \\
\hline Std/mean & 0.30 & 0.46 & 0.13 & 0.44 & 0.58 & 0.18 & \\
\hline
\end{tabular}

where carbon-cycle parameters are defined by $\beta \equiv$ $\left.\frac{\partial F}{\partial C_{\text {atmos }}}\right|_{0}$ and $\left.\gamma \equiv \frac{\partial F}{\partial T}\right|_{0}$, and $\beta \Delta C_{\text {atmos }}$ is referred to as the carbon-concentration feedback and $\gamma \Delta T$ as the carbon-climate feedback; $\beta$ and $\gamma$ measure the slope of the relationship relative to the pre-industrial (with the differentials being evaluated at pre-industrial time marked as 0 ), rather than by the local slope for a later time.

An increase in the land and ocean carbon inventories following an increase in atmospheric carbon is defined by a positive $\beta$, while an increase in these carbon inventories following an increase in surface temperature is defined by a positive $\gamma$. When viewed from an atmospheric perspective, positive values for $\beta$ and $\gamma$ correspond to a negative response and feedback as the atmospheric carbon inventory is decreased, while when viewed from a terrestrial or ocean perspective, these positive values for $\beta$ and $\gamma$ correspond to a positive response and feedback since the land and ocean carbon reserves are enhanced.

\section{Diagnostics of Carbon Inventory Changes for CMIP5 Earth System Models}

The carbon responses and feedbacks are now illustrated for 5 different representative coupled model intercomparison project phase 5 (CMIP5) Earth system models (Table 1); for a fuller range of 7 to 11 CMIP5 models, also see diagnostics by $[14,15]$. All the climate models are forced by an idealised $1 \%$ annual increase in atmospheric $\mathrm{CO}_{2}$ that drives enhanced radiative forcing and leads to surface warming (Fig. 2a, b). This addition of carbon increases each of the atmospheric, land and ocean carbon inventories (Fig. 2c, black, dashed and full lines) with a wider range in the land response than in the ocean response; the ocean uptake may be further interpreted by separating into different carbon pools (Fig. 2d).

\section{Diagnostics of Carbon-Cycle Feedbacks for CMIP5 Earth System Models}

The combined changes in land and ocean carbon inventories are now considered in terms of their separate relationships with atmospheric $\mathrm{CO}_{2}$ and surface temperature. Given the application of a Taylor expansion, $\beta$ should formally be evaluated with no climate change and surface temperature kept constant, while $\gamma$ should be evaluated with atmospheric $\mathrm{CO}_{2}$ kept constant. The carbon-cycle feedback parameters, $\beta$ and $\gamma$, are estimated from the bulk land and ocean carbon changes diagnosed in coupled climate-carbon model experiments with different elements of the carbon-cycle or radiative forcing switched on or off [12-15]; there is also an alternative definition of carbon-cycle feedback parameters based upon the carbon flux to the atmosphere [20], rather than in terms of inventory changes. To diagnose the carbon-cycle feedbacks, three model versions have been traditionally used: a fully coupled, a radiatively coupled and a biogeochemically coupled version:

1. In the fully coupled simulation, the increase in atmospheric $\mathrm{CO}_{2}$ affects the radiative forcing and biogeochemical processes acting in the land and the ocean.

2. In the radiatively coupled simulation, the increase in atmospheric $\mathrm{CO}_{2}$ affects the radiative forcing and leads to associated climate change, while for the land and ocean biogeochemistry the pre-industrial constant atmospheric $\mathrm{CO}_{2}$ is prescribed.

3. In the biogeochemically coupled simulation, the increase in the atmospheric $\mathrm{CO}_{2}$ affects the land and ocean biogeochemical processes, but not the radiative forcing which retains its pre-industrial value.

Any combination of these three runs may be employed to estimate the carbon-cycle feedbacks. However, each 

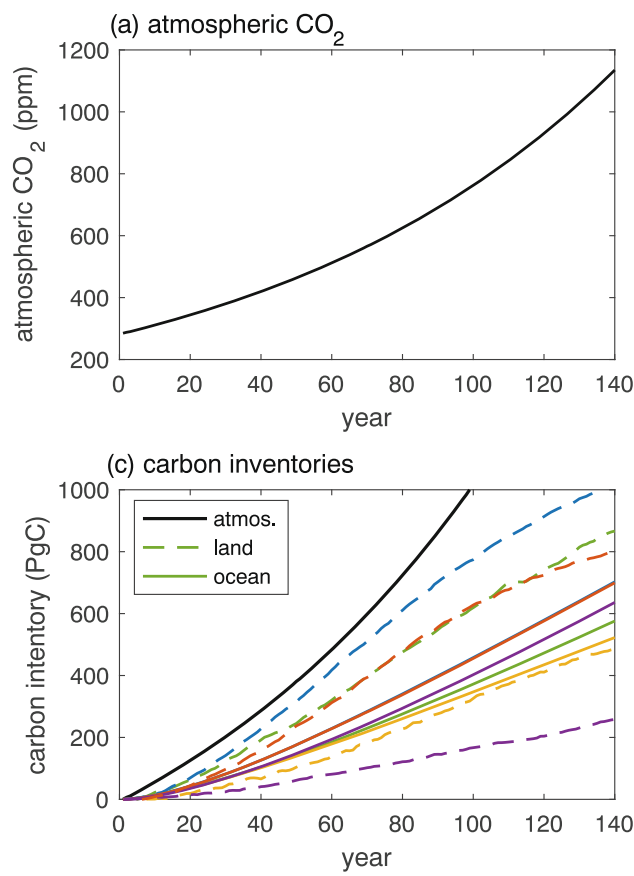

(e) land and ocean carbon inventory change
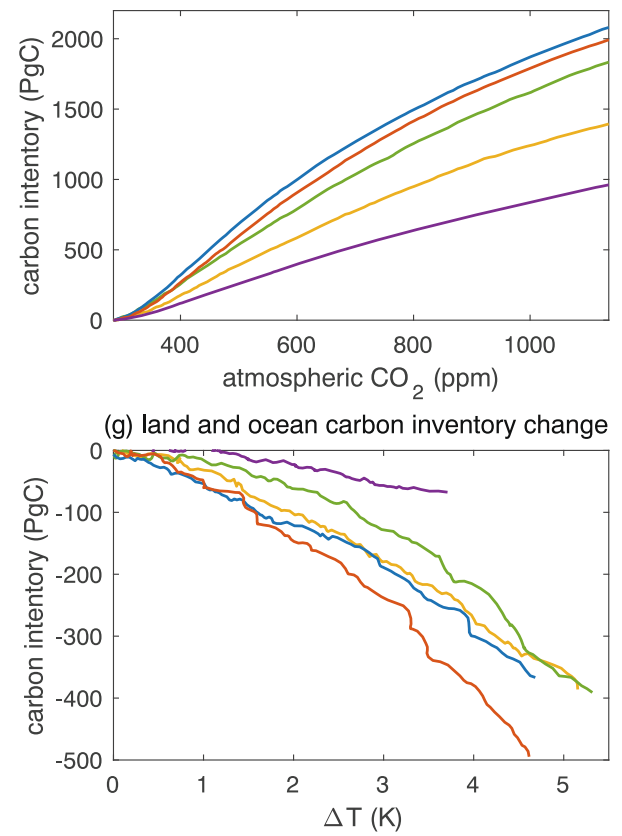

Fig. 2 Response of 5 CMIP5 Earth system models over 140 years (Table 1): (a) an imposed $1 \%$ annual rise in atmospheric $\mathrm{CO}_{2}(\mathrm{ppm})$; (b) the global-mean change in surface air temperature (K); (c) increase in carbon inventories for the atmosphere (black line), the land (dashed lines) and the ocean (full coloured lines); and (d) the separate saturated, disequilibrium and regenerated contributions to the ocean carbon

of the different combinations gives different results due to the nonlinearity of the system, such that the carbon fluxes diagnosed from the sum of the radiatively and the biogeochemically coupled simulations do not add up to that of the fully coupled simulation, and so that the (b) surface warming

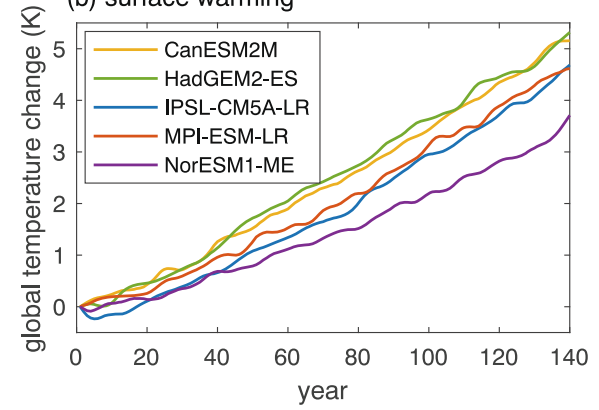

(d) contribution to ocean carbon inventory

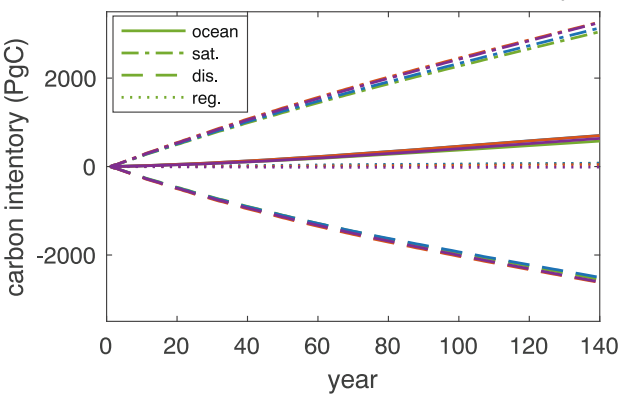

(f) land and ocean carbon-conc. feedback $\beta$

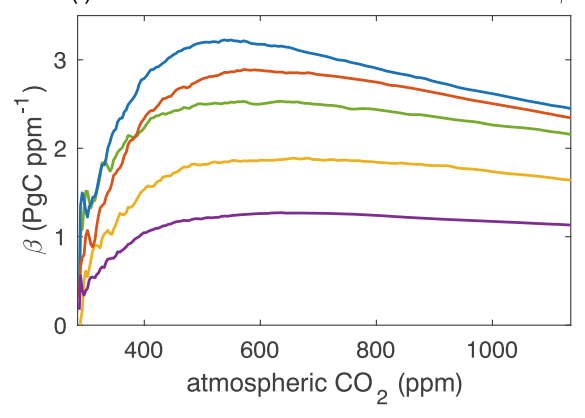

(h) land and ocean carbon-climate feedback $\gamma$

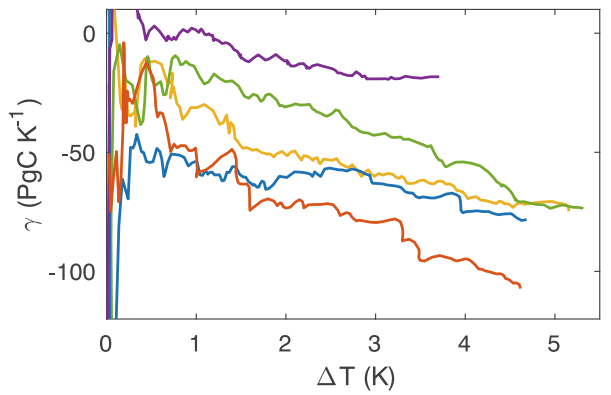

inventory. The changes in the land and ocean carbon inventories $(\mathrm{PgC})$ are presented in terms of separate changes due to changes in (e) atmospheric $\mathrm{CO}_{2}(\mathrm{ppm})$ and (f) its carbon-concentration feedback term, $\beta^{*}=\left(C_{\text {atmos }} / \mathrm{CO}_{2}\right) \beta$ in $\mathrm{PgC} \mathrm{ppm}{ }^{-1}$ and in $(\mathrm{g})$ surface temperature $(\mathrm{K})$ and (h) its carbon-climate feedback term, $\gamma$ in $\mathrm{PgC} \mathrm{K}^{-1}$

feedbacks from each of these combinations have different interpretations [15].

Here, we use the fully coupled simulation combined with the biogeochemically coupled simulations to estimate the feedbacks, such that the carbon-concentration feedback 
parameter, $\beta$, is estimated directly from the biogeochemically coupled run and the carbon-climate feedback parameter, $\gamma$, is estimated from the difference between the fully coupled and the biogeochemically coupled runs and represents the effect of climate change under rising atmospheric $\mathrm{CO}_{2}$.

The combined land and ocean carbon uptake increases with rising atmospheric $\mathrm{CO}_{2}$ with the slope of the curve relative to the pre-industrial peaking around $500 \mathrm{ppm}$ (Fig. 2e). The carbon-concentration feedback parameter, $\beta$, measures the slope of this curve, so that $\beta$ increases to a maximum at around $500 \mathrm{ppm}$ and then decreases for higher atmospheric $\mathrm{CO}_{2}$ (Fig. 2f). This shape of response suggests that there is a competition of different mechanisms acting to enhance or diminish the rate of land and ocean uptake of carbon with increasing atmospheric $\mathrm{CO}_{2}$.

In contrast, the combined land and ocean carbon inventories decrease with the rising surface temperature (Fig. 2g) and, in most models, the rate of decrease becomes larger with more pronounced surface warming. The carbonclimate feedback parameter, $\gamma$, measures the slope of this curve relative to the pre-industrial and is negative with increasingly negative values with a higher surface temperature (Fig. 2h).

The dependence of the land and ocean carbon inventories on atmospheric $\mathrm{CO}_{2}$ (Fig. 2e, f) implies that carboncycle parameters should only be compared for climate model integrations using the same forcing scenarios (as in Table 1), otherwise there will be automatically much larger differences due to the amount of carbon emitted to the atmosphere.

\section{Separation of Land and Ocean Carbon-Cycle Feedbacks}

The carbon response of the combined land and ocean system has so far been considered and naturally, it is of interest to separate their responses. However, the inter-connection of the land and ocean carbon systems makes this separation into individual land and ocean carbon responses more ambiguous than expected. For example, a carbon uptake by the land system may lead to an immediate decrease in atmospheric carbon, which will then cause an outgassing of carbon from the ocean to the atmosphere, acting to partly offset the original decrease in atmospheric carbon and instead decrease the ocean store of carbon. Hence, the coupled nature of the carbon system means that any changes in atmospheric carbon estimated solely from a change in a land or ocean carbon inventory should be viewed as an upper bound, as compensation by the other part of the carbon system is ignored.

Accepting this caveat, the carbon inventory changes are next separately considered in terms of global diagnostics for the land and ocean in terms of their contributions to $\beta$ and $\gamma$, such that $\beta=\beta_{\text {land }}+\beta_{\text {ocean }}$ and $\gamma=\gamma_{\text {land }}+\gamma_{\text {ocean }}$. The local regional responses may differ from these globalmean responses, particularly by having different signs for the climate response, $\gamma$.

\section{Terrestrial Carbon-Cycle Feedbacks}

The change in the land carbon inventory may be written in terms of the linear carbon-cycle framework (7) as

$\Delta C_{\text {land }}=\beta_{\text {land }} \Delta C_{\text {atmos }}+\gamma_{\text {land }} \Delta T$.

The carbon-concentration feedback, $\beta_{\text {land }} \Delta C_{\text {atmos }}$, represents how the land carbon inventory responds to higher atmospheric $\mathrm{CO}_{2}$. The primary contribution is through how photosynthesis is stimulated by elevated atmospheric $\mathrm{CO}_{2}$, so increasing the land carbon inventory and decreasing the atmospheric response to carbon emissions. There is positive $\beta_{\text {land }}$ with carbon emissions with the highest values peaking for atmospheric $\mathrm{CO}_{2}$ between 500 and $600 \mathrm{ppm}$ (Table 1 for 5 different Earth system models) [12, 14].

The carbon-climate feedback, $\gamma_{\text {land }} \Delta T$, represents the effects of a warmer climate on the land carbon inventory. Surface warming leads to an increase in plant and soil respiration, so acting to decrease the land carbon inventory. Changes in precipitation and nutrient availability also alter plant photosynthesis and changes in the abundance and distribution of vegetation. The carbon-climate feedback parameter, $\gamma_{\text {land }}$, is negative and becomes increasingly negative with greater surface warming (Table 1) [12, 14].

To gain insight, the terrestrial carbon pool may be separated into carbon pools associated with vegetation and soil [26],

$\Delta C_{\text {land }}=\Delta C_{\mathrm{veg}}+\Delta C_{\text {soil }}$

The total carbon stored in vegetation is increased by photosynthesis and reduced by plant respiration and litter fall, while the soil carbon is increased with litter fall and decreased with soil respiration [27]; further multiple components may be included, such as soft plant and woody components with the soft plant material decaying more rapidly than woody material. The land carbon feedback parameters, $\beta_{\text {land }}$ and $\gamma_{\text {land }}$, may then be connected mechanistically to carbon cycled within these vegetation and soil pools. For example, Earth system model diagnostics reveal elevated atmospheric $\mathrm{CO}_{2}$ stimulating plant productivity, as well as enhanced litter fall and heterotrophic respiration, which leads to a larger $\beta_{\text {land }}$ [26].

In summary, changes in terrestrial carbon storage are controlled by a balance between an increase in carbon storage from photosynthesis being stimulated by increased atmospheric $\mathrm{CO}_{2}$ and partly opposed by a decrease in carbon storage from plant and soil respiration being 
enhanced by surface warming [27, 28]. These responses are also affected by changes in rainfall, nutrient availability and dynamic changes in vegetation $[29,30]$.

\section{Ocean Carbon-Cycle Feedbacks}

The change in the ocean carbon inventory may be again written in terms of a linear carbon-cycle framework (7) as

$\Delta C_{\text {ocean }}=\beta_{\text {ocean }} \Delta C_{\text {atmos }}+\gamma_{\text {ocean }} \Delta T$.

The carbon-concentration feedback, $\beta_{\text {ocean }} \Delta C_{\text {atmos }}$, represents how the ocean carbon inventory responds to higher atmospheric $\mathrm{CO}_{2}$. The primary contribution is how the ocean takes up more carbon in the form of dissolved inorganic carbon, DIC, with higher atmospheric $\mathrm{CO}_{2}$. There is a positive $\beta_{\text {ocean }}$ with carbon emissions with the highest values peaking for atmospheric $\mathrm{CO}_{2}$ around $500 \mathrm{ppm}$ (Table 1) [12, 14, 15]. This bell-shaped response is due to the ocean increasing its ability to hold more carbon with higher atmospheric $\mathrm{CO}_{2}$ until this increase is partly offset by the opposing effect of the ocean becoming more acidic, which inhibits the ability to hold more carbon.

The carbon-climate feedback, $\gamma_{\text {ocean }} \Delta T$, represents the effects of a warmer climate on the ocean carbon inventory. The possible effects of a warmer climate include (i) reduced ventilation of the ocean interior involving a thinner surface mixed layer that acts as the interface between the atmosphere and ocean, an increase in ocean stratification and a decrease in the ocean overturning circulation; (ii) a decrease in solubility of carbon with warmer waters; and (iii) a possible weakening in biological drawdown of carbon. The carbon-climate feedback parameter, $\gamma_{\text {ocean }}$, is negative (Table 1) and becomes increasingly negative with greater surface warming $[12,14,15]$, probably due to how ocean ventilation is inhibited in a warmer climate [31]. However, this temperature-driven climate change in the carbon response is much larger for the land than the ocean on a centennial timescale (Table 1).

To gain insight into the changes in the ocean carbon inventory, the ocean dissolved inorganic carbon, DIC, may be separated into preformed and regenerated carbon pools,

$\mathrm{DIC}=\mathrm{DIC}_{\text {pre }}+\mathrm{DIC}_{\text {reg }}$,

with the preformed carbon, $\mathrm{DIC}_{\text {pre }}$, representing the carbon physically transferred from the surface ocean and the regenerated carbon, $\mathrm{DIC}_{\text {reg }}$, representing the carbon that is regenerated from biological material. The preformed carbon may be further separated into saturated and disequilibrium pools, such that

$\mathrm{DIC}=\mathrm{DIC}_{\mathrm{sat}}+\mathrm{DIC}_{\mathrm{reg}}+\mathrm{DIC}_{\mathrm{dis}}$,

where $\mathrm{DIC}_{\mathrm{sat}}$ represents the amount of carbon the ocean holds if in equilibrium with atmospheric $\mathrm{CO}_{2}$ at that time and $\mathrm{DIC}_{\mathrm{dis}}$ represents the extent that the ocean carbon departs from this equilibrium with the atmosphere [32-34]. These pools of dissolved inorganic carbon equate to ocean carbon inventories when integrating the DIC by mass over the global ocean, such that

$\Delta C_{\text {ocean }}=\Delta C_{\text {ocean, sat }}+\Delta C_{\text {ocean, reg }}+\Delta C_{\text {ocean, dis }}$.

For the $1 \%$ annual increase in atmospheric $\mathrm{CO}_{2}$ experiments, the saturated ocean carbon inventory strongly increases in time following the rise in atmospheric $\mathrm{CO}_{2}$, although the rate of these increases slightly declines for higher atmospheric $\mathrm{CO}_{2}$ (Fig. 2d, dash dot lines). There is only a very slight increase in the regenerated carbon inventory over this centennial timescale (Fig. 2d, dotted lines). Instead the disequilibrium carbon is large and negative (Fig. 2d, dashed lines), representing how the ocean carbon is not keeping pace with the saturated carbon expected if there was an atmosphere-ocean equilibrium for carbon. This disequilibrium carbon is affected with the rate of increase in atmospheric $\mathrm{CO}_{2}$ and the rate of ocean ventilation, controlling the carbon transfer from the ocean surface mixed layer into the ocean thermocline and deep ocean. There is an overall ocean carbon uptake (Fig. 2d, full lines) so that the positive increase in the saturated response is not completely offset by the negative increase in the disequilibrium carbon.

The carbon-cycle feedback parameters, $\beta_{\text {ocean }}$ and $\gamma_{\text {ocean }}$, may be diagnosed for the preformed and regenerated terms [18], and each of the saturated, regenerated and disequilibrium terms making up ocean DIC [31]. The advantage of this separation is that the saturated terms for $\beta_{\text {ocean }}$ and $\gamma_{\text {ocean }}$ may be defined from theory, although the disequilibrium terms, especially for $\gamma_{\text {ocean }}$ still need to be diagnosed from model integrations.

The carbon-concentration feedback parameter, $\beta_{\text {ocean }}$, is positive and peaks in magnitude at between 400 and $500 \mathrm{ppm}$ with variations in atmospheric $\mathrm{CO}_{2}$. The saturated contribution to $\beta_{\text {ocean }}$ is strongly positive representing how the ocean holds more carbon with an increase in atmospheric $\mathrm{CO}_{2}$. This saturated contribution decreases in magnitude though with increasing atmospheric $\mathrm{CO}_{2}$ due to the ocean taking up more carbon and acidifying and so decreasing its capacity to buffer changes in atmospheric $\mathrm{CO}_{2}$. The disequilibrium contribution to $\beta_{\text {ocean }}$ is negative and represents the extent that the ocean has not kept pace with an atmosphereocean equilibrium during the period of increasing atmospheric $\mathrm{CO}_{2}$. The disequilibrium contribution to $\beta_{\text {ocean }}$ decreases in magnitude with increasing atmospheric $\mathrm{CO}_{2}$.

The carbon-climate feedback parameter, $\gamma_{\text {ocean }}$, becomes generally more negative with greater surface warming, which involves three different contributions: (i) surface warming leads to the solubility of the ocean decreasing, making the saturated carbon pool smaller for the same atmospheric $\mathrm{CO}_{2}$, so that the saturated contribution to 
$\gamma_{\text {ocean }}$ is negative; (ii) surface warming decreases ocean ventilation and lengthens the residence time below the surface ocean, which increases the regenerated nutrient and carbon pool [15], so that the regenerated contribution to $\gamma_{\text {ocean }}$ is positive; and (iii) the disequilibrium carbon response is sensitive to both changes in the saturated carbon and the ventilation, and the change in disequilibrium carbon provides a negative contribution to $\gamma_{\text {ocean }}$ when evaluated from the difference between the fully coupled and the biogeochemically coupled model simulations. There is an overall negative contribution from the changes in solubility and disequilibrium dominating over the changes in the regenerated carbon [35].

In summary, the carbon storage in the ocean increases with elevated atmospheric $\mathrm{CO}_{2}$, controlled by ocean carbonate chemistry, although this additional ocean carbon uptake decreases in a warmer climate from a thinning of the mixed layer, weaker ventilation and overturning, and a decrease in solubility and possible changes in biology.

\section{Summary for Carbon-Cycle Feedbacks for the Land and Ocean}

Carbon-cycle feedbacks represent the extent that the land and ocean carbon inventories respond to the effects of carbon emissions, overall acting to decrease the expected rise in atmospheric $\mathrm{CO}_{2}$ and so provide a negative response and feedback to the original perturbation in the atmosphere; as illustrated in Table 1 and in other diagnostics of Earth system models [12-14]. The dominant contribution is from the effect of the carbon-concentration feedback, $\beta \Delta C_{\text {atmos }}>0$, acting to enhance the combined land and ocean carbon inventories. There is a smaller effect of the carbon-climate feedback, $\gamma \Delta T<0$, with a warmer climate acting to reduce the rise in the combined land and ocean carbon inventories.

\section{Limitations of the Carbon-Cycle Feedback Approach}

The carbon-cycle feedback approach is very useful by providing an accessible measure of how the carbon system evolves in a climate model and may be used to define differences in the carbon cycling of these climate models [11-14]. However, at the same time, there are several limitations in the carbon-cycle framework that are important to acknowledge:

1. The original linearisation of the function defining the carbon state of the climate system, $F$ in Eq. 6, ignores non-linear dependence in how carbon inventories alter with atmospheric carbon and surface temperature (represented by the curvature of the contours on Fig. 1b, c).
This non-linear error is important in providing uncertainty in the estimate of the carbon feedback [13-15];

2. The land and ocean carbon systems may more directly be controlled by other variables. For the land, the dependent variables may be the water supply to plants and the nutrient availability to allow plants to photosynthesise more with elevated atmospheric $\mathrm{CO}_{2}$. This dependence on water and nutrient supply may not be captured by a general dependence on temperature. For the ocean, the dependent variable may be the extent of ocean ventilation, which is more directly related to the thickness of the surface mixed layer, the subduction rate defining the strength of exchange between the mixed layer and the ocean interior, and the strength of meridional overturning. The pattern of climate change is also potentially important in altering the regional mechanisms controlling the land and ocean carbon store;

3. By themselves, the carbon-cycle feedback parameters, $\beta$ and $\gamma$, are usually diagnosed from differences in climate-model experiments with selected components switched on and off [12-14] and so are difficult to diagnose from observations. While estimates of the carbon-cycle feedback parameters have been made using model simulations constrained by observations [36], it is important that the observations and model simulations cover the same period, rather than compare inferences made over a historical period with relatively small changes and over a climate projection with very large changes.

While noting these limitations, we next consider how the carbon-cycle feedback parameters, $\beta$ and $\gamma$, representing the effects of a carbon response and feedback, may be converted into a carbon response and feedback parameter with the same units as the physical climate feedback parameter.

\section{Connecting to a Carbon Response and Feedback Parameter}

Our goal is now to connect the land and ocean carbon changes to a carbon response and feedback parameter following $[13,37]$, which is directly analogous to a physical climate feedback parameter. Both the carbon and climate feedback parameters when multiplied by a change in surface temperature provides a change in radiative forcing in $\mathrm{W} \mathrm{m}{ }^{-2}$, which defines aspects of the climate response to carbon forcing. To make this connection as simple as possible, we choose to combine the effects of a carbon response and feedback together, even though in the physical system, the climate response involving planetary heat uptake and the climate feedback are usually separated from each other. 


\section{Derivation for the Carbon Response and Feedback Parameter}

The radiative forcing expected from carbon emissions, $R\left(\Delta C_{\mathrm{em}}\right)$, may be defined in terms of the radiative forcing due to the increase in atmospheric carbon, $R\left(\Delta C_{\text {atmos }}\right)$, plus the radiative forcing that would otherwise have occurred, $R_{\mathrm{CO}_{2}}^{\text {feedback}}$, representing the effect of a combined carbon response and feedback due to changes in the land and ocean carbon inventories,

$$
\underbrace{R\left(\Delta C_{\mathrm{em}}\right)}_{\begin{array}{r}
\text { forcing from } \\
\text { emissions }
\end{array}}=\underbrace{R\left(\Delta C_{\mathrm{atmos}}\right)}_{\begin{array}{c}
\text { atmospheric } \\
\text { forcing }
\end{array}}+\underbrace{R_{\mathrm{CO}_{2}}^{\text {feedback }}}_{\begin{array}{l}
\text { land and ocean } \\
\text { response and feedback }
\end{array}} .
$$

Here the carbon response and feedback, $R_{\mathrm{CO}_{2}}^{\text {feedback }}$, are defined as positive for a land and ocean uptake of carbon, so acts to make the radiative forcing in the atmosphere, $R\left(\Delta C_{\text {atmos }}\right)$, smaller in magnitude than the radiative forcing expected from carbon emissions, $R\left(\Delta C_{\mathrm{em}}\right)$, where $\Delta$ represents the change since the pre-industrial period; see Fig. 1 of [37] for this separation of radiative forcing and feedback. Next consider how $R\left(\Delta C_{\text {atmos }}\right)$ and $R_{\mathrm{CO}_{2}}^{\text {feedack }}$ on the right-hand side of (14) may be expressed.

Firstly, in an empirical global radiative balance [38, 39], the radiative forcing from atmospheric $\mathrm{CO}_{2}, R\left(\Delta C_{\text {atmos }}\right)$, drives a climate feedback and climate response, which are expressed in terms of a physical feedback term, $\lambda_{\text {climate }} \Delta T$, plus a planetary heat uptake, $N$,

$$
\underbrace{R\left(\Delta C_{\text {atmos }}\right)}=\underbrace{\lambda_{\text {climate }} \Delta T}+\underbrace{N},
$$

atmospheric forcing climate feedback heat uptake

where $R$ is expressed as a global-mean radiative forcing per unit surface area in $\mathrm{W} \mathrm{m}^{-2}$ and is a function of the change in the atmospheric carbon inventory $\Delta C_{\text {atmos }}, N$ is the global-mean heat uptake per unit area in $\mathrm{W} \mathrm{m}^{-2}$, $\lambda_{\text {climate }}$ is the physical climate feedback parameter in $\mathrm{W} \mathrm{m}^{-2} \mathrm{~K}^{-1}$ and $\Delta T$ is the change in the global-mean surface air temperature since the pre-industrial era in $\mathrm{K}$. The climate feedback parameter includes the effect of the Planck feedback of enhanced longwave radiation from a warmer surface together with the radiative feedbacks from changes in water vapour, surface albedo and cloud (Fig. 3, grey and black circles from [7]). By defining each of the radiative terms in Eq. 15 as positive, the Planck radiative response of enhanced longwave radiation from a warmer surface is represented by a positive $\lambda_{\text {climate }}$, which provides a negative feedback acting to partly offset the effect of the radiative forcing and decrease the magnitude of surface warming.

Secondly, drawing upon the analogy with the physical climate system, we define the radiative response and feedback from the changes in the land and ocean carbon inventories, $R_{\mathrm{CO}_{2}}^{\text {feedback }}$, in terms of the product of a carbon response and feedback parameter, $\lambda_{\text {carbon }}$, and the change in global-mean surface temperature, $\Delta T$,

$R_{\mathrm{CO}_{2}}^{\text {feedback }} \equiv \lambda_{\text {carbon }} \Delta T$,

where $\lambda_{\text {carbon }}$ is in $\mathrm{W} \mathrm{m}^{-2} \mathrm{~K}^{-1}$ and $\Delta T$ in $\mathrm{K}$.

Hence, combining (14) to (16), the global-mean radiative balance may be expressed in terms of the radiative forcing expected from carbon emissions, $R\left(\Delta C_{\mathrm{em}}\right)$, as

$$
\underbrace{R\left(\Delta C_{\mathrm{em}}\right)}_{\begin{array}{c}
\text { forcing from } \\
\text { emissions }
\end{array}}=\underbrace{\lambda_{\text {carbon }} \Delta T}_{\begin{array}{c}
\text { carbon response } \\
\text { and feedback }
\end{array}}+\underbrace{\lambda_{\text {climate }} \Delta T}_{\text {climate }}+\underbrace{N}_{\text {heat uptake }} .
$$

The radiative forcing expected from emissions, $R\left(\Delta C_{\mathrm{em}}\right)$, in Eq. 17 may then be viewed as being offset by a carbon response and feedback, $\lambda_{\text {carbon }} \Delta T$, representing the land and ocean removal of carbon from the atmosphere, plus a climate feedback, $\lambda_{\text {climate }} \Delta T$, radiating heat to space, and plus a heat uptake, $N$, representing a planetary gain in heat [37].

In order to derive an expression for $\lambda_{\text {carbon }}$ in Eq. 17, we now apply a series of approximations following [13]:

1. The radiative forcing from atmospheric $\mathrm{CO}_{2}$ is usually represented by a saturating logarithmic dependence [40], $R\left(\Delta C_{\text {atmos }}(t)\right)=a \ln \left(C_{\text {atmos }}(t) / C_{\text {atmos }}\left(t_{0}\right)\right)$, which may be linearly approximated by

$R\left(\Delta C_{\mathrm{atmos}}\right) \simeq \phi \Delta C_{\mathrm{atmos}}$,

where $a$ is a radiative forcing coefficient for atmospheric $\mathrm{CO}_{2}$ and $\phi \simeq a / C_{\text {atmos }}\left(t_{1}\right)$ is a linearised estimate of the slope of the radiative forcing with respect to the atmospheric carbon inventory (with $C_{\text {atmos }}\left(t_{1}\right)$ the atmospheric carbon inventory at the time $t_{1}$ when the radiative forcing is estimated); $\phi$ has a mean and standard deviation of $0.004 \pm 0.0006 \mathrm{~W} \mathrm{~m}^{-2} \mathrm{PgC}^{-1}$ when evaluated from years 121 to 140 in our diagnostics of 5 Earth system models (Table 2).

2. The radiative forcing, $R_{\mathrm{CO}_{2}}^{\text {feedback }}$, from the carbon response and feedback of the land and ocean system is assumed to depend upon the combined land and ocean carbon inventory changes, $\Delta C_{\text {land }}+\Delta C_{\text {ocean }}$, which is linearly connected to the atmospheric carbon and global-mean temperature (7) with a functional relationship given by

$R_{\mathrm{CO}_{2}}^{\text {feedback }}=R_{\mathrm{CO}_{2}}^{\text {feedback }}\left(\beta \Delta C_{\text {atmos }}+\gamma \Delta T\right)$,

and then approximated as in Eq. 18 by

$R_{\mathrm{CO}_{2}}^{\text {feedback }} \simeq \phi\left(\beta \Delta C_{\text {atmos }}+\gamma \Delta T\right)$.

3. Returning to the empirical global radiative balance (15), the planetary heat uptake is approximated by a diffusive 


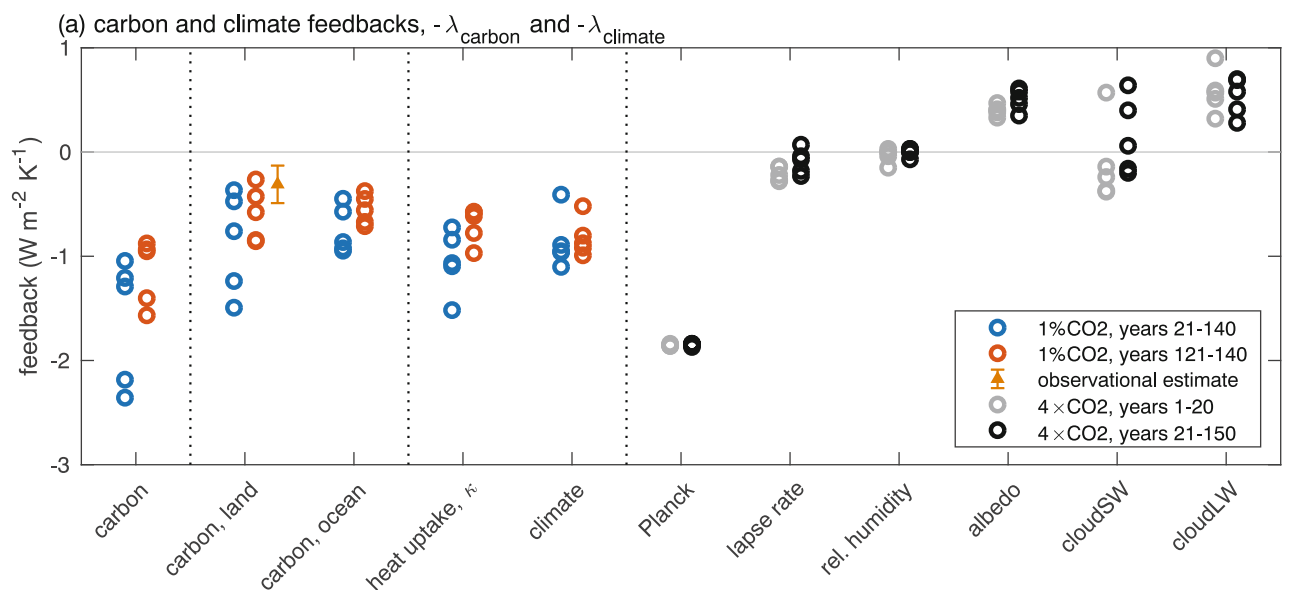

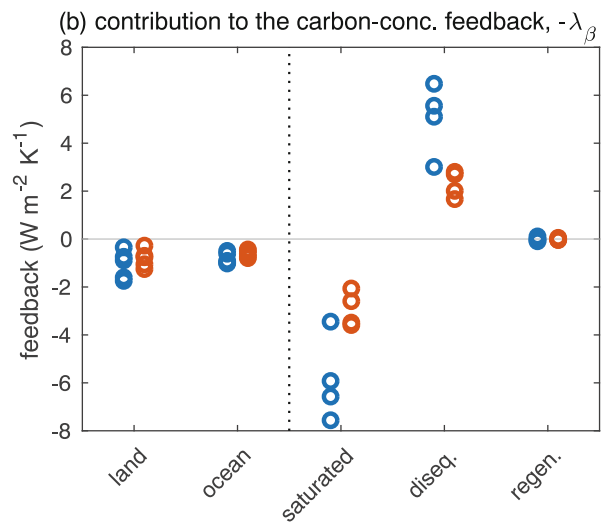

Fig. 3 (a) Carbon response and feedback parameter, $-\lambda_{\text {carbon }}$, for the land and ocean, the efficiency of heat uptake, $-\kappa$ and the climate feedback parameter, $-\lambda_{\text {climate, }}$ all in $\mathrm{W} \mathrm{m}^{-2} \mathrm{~K}^{-1}$; their values are plotted multiplied by a negative sign, so that an overall positive value indicates surface warming and a positive feedback for surface temperature. Diagnostics follow [13] and are from 5 CMIP5 Earth system models (Table 1) with a $1 \%$ annual increase in atmospheric $\mathrm{CO}_{2}$ for years 21 to 140 (blue circles) and years 121 to 140 (orange circles). An estimate of the land carbon feedback parameter from observational analyses (orange triangle for the mean and bounds for two standard deviations) is included following [37], which accounts for an ocean adjustment. In

closure, $N=\kappa \Delta T$,

$R\left(\Delta C_{\text {atmos }}\right) \simeq\left(\lambda_{\text {Climate }}+\kappa\right) \Delta T$.

so providing a link between the change in the atmospheric carbon inventory and surface temperature change using Eq. 18, such that

$\phi \Delta C_{\mathrm{atmos}} \simeq\left(\lambda_{\text {Climate }}+\kappa\right) \Delta T$,

where $\kappa$ is the ocean heat uptake efficiency in a closure for ocean heat uptake; $\kappa$ has a mean and standard deviation of $0.70 \pm 0.17 \mathrm{~W} \mathrm{~m}^{-2} \mathrm{~K}^{-1}$ when evaluated from years 121 to 140 in our diagnostics of 5 Earth system models (Table 2).

Combining the definition of the carbon response and feedback parameter $\lambda_{\text {carbon }}$ in Eqs. 16 with Eqs. 20 and 22,

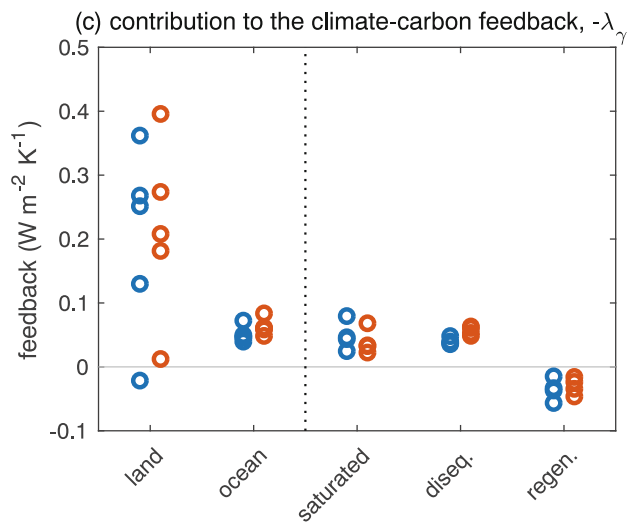

addition, the components of the physical climate feedback, $-\lambda_{\text {climate }}$, from Planck, lapse rate, relative humidity, surface albedo, shortwave and longwave radiation changes from clouds are included for the same climate models from [7] for a $4 \times \mathrm{CO}_{2}$ experiments from years 1 to 20 (grey circles) and years 21 to 150 (black circles). The carbon feedback parameter, $\lambda_{\text {carbon }}$, is separated into contributions depending on (b) the carbon-concentration feedback, $\lambda_{\beta}$, and (c) the carbon-climate feedback, $\lambda_{\gamma}$, connected with changes in the land and ocean carbon inventories, and the saturated, disequilibrium and regenerated ocean carbon inventories

then provides

$R_{\mathrm{CO}_{2}}^{\mathrm{feedback}} \equiv \lambda_{\text {carbon }} \Delta T \simeq\left(\beta\left(\lambda_{\text {Climate }}+\kappa\right)+\phi \gamma\right) \Delta T$,

so that $\lambda_{\text {carbon }}$ is defined by

$\lambda_{\text {carbon }} \simeq \underbrace{\beta\left(\lambda_{\text {climate }}+\kappa\right)}+\underbrace{\phi \gamma}$.

carbon-concentration carbon-climate

response and feedback response and feedback

The carbon response and feedback parameter, $\lambda_{\text {carbon }}$, then is made up of two contributions, each including combined carbon and climate effects:

1. The carbon-concentration cycle parameter, $\beta$, measuring a dependence on atmospheric carbon, multiplied by the sum of the physical climate feedback, $\lambda_{\text {climate }}$, and transient heat uptake via $\kappa$, and 
Table 2 Carbon-cycle feedback parameters, $\lambda_{\text {carbon }}$, separated into land and ocean contributions, and then further into $\beta$ and $\gamma$ contributions from 5 CMIP5 Earth system models

\begin{tabular}{|c|c|c|c|c|c|c|c|c|c|c|}
\hline Model & $\begin{array}{l}\lambda_{\text {carbon }} \\
\mathrm{Wm}^{-2} \mathrm{~K}^{-1}\end{array}$ & $\begin{array}{l}\lambda_{\text {land }} \\
\mathrm{Wm}^{-2} \mathrm{~K}^{-1}\end{array}$ & $\begin{array}{l}\lambda_{\text {ocean }} \\
\mathrm{Wm}^{-2} \mathrm{~K}^{-1}\end{array}$ & $\begin{array}{l}\lambda_{\beta, \text { land }} \\
\mathrm{Wm}^{-2} \mathrm{~K}^{-1}\end{array}$ & $\begin{array}{l}\lambda_{\beta, \text { ocean }} \\
\mathrm{Wm}^{-2} \mathrm{~K}^{-1}\end{array}$ & $\begin{array}{l}\lambda_{\gamma, \text { land }} \\
\mathrm{Wm}^{-2} \mathrm{~K}^{-1}\end{array}$ & $\begin{array}{l}\lambda_{\gamma, \text { ocean }} \\
\mathrm{Wm}^{-2} \mathrm{~K}^{-1}\end{array}$ & $\begin{array}{l}\lambda_{\text {climate }} \\
\mathrm{Wm}^{-2} \mathrm{~K}^{-1}\end{array}$ & $\begin{array}{l}\kappa \\
\mathrm{Wm}^{-2} \mathrm{~K}^{-1}\end{array}$ & $\begin{array}{l}\phi \\
\mathrm{Wm}^{-2} \mathrm{PgC}^{-1}\end{array}$ \\
\hline CanESM2 & 0.88 & 0.43 & 0.45 & 0.70 & 0.50 & -0.27 & -0.049 & 0.92 & 0.57 & 0.0045 \\
\hline HadGEM2-ES & 0.96 & 0.58 & 0.38 & 0.76 & 0.44 & -0.18 & -0.060 & 0.52 & 0.61 & 0.0034 \\
\hline IPSL-CM5A-LR & 1.40 & 0.84 & 0.56 & 1.05 & 0.62 & -0.21 & -0.059 & 0.80 & 0.58 & 0.0036 \\
\hline MPI-ESM-LR & 1.58 & 0.86 & 0.72 & 1.25 & 0.80 & -0.40 & -0.084 & 0.99 & 0.78 & 0.0048 \\
\hline Nor-ESM1-ME & 0.94 & 0.27 & 0.67 & 0.28 & 0.73 & -0.01 & -0.062 & 0.88 & 0.97 & 0.0036 \\
\hline Mean & 1.16 & 0.60 & 0.56 & 0.81 & 0.62 & -0.21 & -0.063 & 0.82 & 0.70 & 0.0040 \\
\hline Std & 0.32 & 0.26 & 0.14 & 0.37 & 0.15 & 0.14 & 0.013 & 0.18 & 0.17 & 0.0006 \\
\hline Std/mean & 0.28 & 0.43 & 0.25 & 0.46 & 0.24 & 0.67 & 0.21 & 0.22 & 0.24 & 0.15 \\
\hline
\end{tabular}

These carbon-feedback parameters are compared with climate feedback parameter, $\lambda_{\text {climate }}$, ocean heat uptake efficiency, $\kappa$, and derivative of radiative forcing from $\mathrm{CO}_{2}$ on the atmospheric carbon inventory, $\phi$. All of these parameters are evaluated from years 121 to 140 for the CMIP5 Earth system models forced by a $1 \%$ atmospheric $\mathrm{CO}_{2}$ annual increase

2. The carbon-climate cycle parameter, $\gamma$, measuring a dependence on climate change, multiplied by a dependence of the radiative forcing on atmospheric carbon, $\phi$.

The carbon and climate responses and feedbacks are directly connected to each other through the carbon response and feedback parameter, $\lambda_{\text {carbon }}$, being proportional to the sum of the physical climate feedback parameter, $\lambda_{\text {climate }}$, and the ocean heat uptake efficiency, $\kappa$, plus the effect of the carbon-climate parameter, $\gamma$, in Eq. 24. A stronger physical climate feedback, $\lambda_{\text {climate }}$, such as with the Planck response dominating, acts to decrease the magnitude of surface warming, which in turn enhances the ability of the combined land and ocean uptake of carbon and provides a stronger carbon response offsetting the effect of carbon emissions. In a similar manner, a greater ocean heat uptake efficiency, $\kappa$, leads to a reduction in the magnitude of surface warming, so similarly increases the combined land and ocean uptake of carbon.

\section{Carbon Response and Feedback Parameter Diagnosed from Earth System Models}

The carbon response and feedback parameter, $\lambda_{\text {carbon }}$, is diagnosed using Eq. 24 from the combination of $\beta$, $\gamma, \lambda_{\text {climate }}, \kappa$ and $\phi$ for each of the 5 Earth system models: $\lambda_{\text {carbon }}$ ranges from 0.88 to $1.58 \mathrm{~W} \mathrm{~m}^{-2} \mathrm{~K}^{-1}$ for the 5 models with a mean and standard deviation of $1.16 \pm 0.32 \mathrm{~W} \mathrm{~m}^{-2} \mathrm{~K}^{-1}$ diagnosed from years 121 to 140 (Table 2); here, $\phi$ is estimated from the local slope of the radiative forcing versus atmospheric carbon inventory for years 121 to 140 using $R\left(\Delta C_{\text {atmos }}(t)\right)=$ $a \ln \left(C_{\text {atmos }}(t) / C_{\text {atmos }}\left(t_{0}\right)\right)$, with $a$ from [41].
A positive $\lambda_{\text {carbon }}$ represents the effect of an increased land and ocean carbon inventory, so acting to decrease the atmospheric carbon inventory, reduce the magnitude of the additional radiative forcing from atmospheric $\mathrm{CO}_{2}$ and so decreases surface warming. Hence, a positive $\lambda_{\text {carbon }}$ is acting as a negative feedback for surface temperature, so these diagnostics are plotted with a negative sign in Fig. 3 to have the same convention as physical feedbacks.

There are comparable contributions with the carbon feedback parameter from the land and ocean: $\lambda_{\text {carbon }}$ for the land ranges from 0.27 to $0.86 \mathrm{~W} \mathrm{~m}^{-2} \mathrm{~K}^{-1}$, while $\lambda_{\text {carbon }}$ for the ocean ranges from 0.38 to $0.72 \mathrm{~W} \mathrm{~m}^{-2} \mathrm{~K}^{-1}$ (Table 2). The land and ocean $\lambda_{\text {carbon }}$ are made up of positive contributions for $\lambda_{\beta} \equiv \beta\left(\lambda_{\text {climate }}+\kappa\right)$ and smaller negative contribution from $\lambda_{\gamma} \equiv \phi \gamma$ in Eq. 24, although the latter ocean term is much smaller in magnitude (Fig. 3b,c; Table 2).

The inter-model spread in the estimates of the carbon feedback parameter reduces in time with a greater spread when diagnosed from years 21 to 140, than over the last two decades of the integration (Fig. 3, blue and orange circles).

\section{Observational Estimate of the Land Carbon Feedback Parameter}

The radiative feedback from the land may again be defined in terms of a carbon feedback parameter for the land multiplied by the change in surface temperature,

$R_{\mathrm{CO}_{2} \text {, land }}^{\text {feedback }}=\lambda_{\text {carbon, land }} \Delta T$.

Following [37], the carbon feedback parameter for the land may be connected to the change in the land carbon inventory, $\Delta C_{\text {land }}$,

$\lambda_{\text {carbon,land }}=\frac{a}{I_{B}} \frac{\Delta C_{\text {land }}}{\Delta T}$, 
where $a$ is a radiative forcing coefficient for atmospheric $\mathrm{CO}_{2}$ and $I_{B}$ is the sum of the atmospheric carbon inventory and the ocean buffered carbon inventory [42, 43]. This relationship takes into account how a change in the land carbon inventory, $\Delta C_{\text {land }}$, leads to changes in both the atmospheric and ocean carbon inventories [37].

Using constraints from the Global Carbon Budget [10], the land carbon feedback parameter, $\lambda_{\text {carbon,land, is estimated }}$ to have a mean and standard deviation of $0.33 \pm 0.09 \mathrm{~W}$ $\mathrm{m}^{-2} \mathrm{~K}^{-1}$ in the present day [37] (Fig. 3a, orange triangle). This estimate of $\lambda_{\text {carbon,land }}$ from Eq. 26 is smaller in magnitude than most of those model diagnostics from Eq. 24 due to different choices in how changes in the carbon inventory affect changes in the partitioning of carbon between the atmosphere and ocean (Fig. 3a, blue and orange circles).

\section{Comparison With Climate Feedback Processes}

The carbon feedback parameter, $\lambda_{\text {carbon }}$, is directly comparable with the climate feedback parameter, $\lambda_{\text {climate, }}$ and the ocean heat uptake efficiency, $\kappa$, all having the same units of $\mathrm{W} \mathrm{m}^{-2} \mathrm{~K}^{-1}$ (Fig. 3a, blue and orange circles): $\lambda_{\text {carbon }}$ is $1.16 \pm 0.32 \mathrm{~W} \mathrm{~m} \mathrm{~m}^{-2} \mathrm{~K}^{-1}$, while $\lambda_{\text {climate }}$ is $0.82 \pm 0.18 \mathrm{~W} \mathrm{~m}^{-2} \mathrm{~K}^{-1}$ and $\kappa$ is $0.70 \pm 0.17 \mathrm{~W} \mathrm{~m}^{-2} \mathrm{~K}^{-1}$ for the mean and standard deviations of the 5 climate models (Table 2).

The different components for $\lambda_{\text {carbon }}$ for the carbonconcentration feedback for the land and ocean and the carbon-climate feedback for the land are comparable to the different contributions to $\lambda_{\text {climate }}$ for the years 121 to 140 (Fig. 3a, grey and black circles).

The Planck response provides enhanced longwave radiation from a warmer surface feedback, defined here as a positive $\lambda$, and so provides a cooling with a negative feedback. This physical feedback is augmented by an overall negative feedback from water vapour through changes in the lapse rate and relative humidity, which is partly opposed by a positive feedback from changes in surface albedo and clouds [7] (Fig. 3a, grey and black circles). The cloud effect includes partly opposing longwave and shortwave effects: a warming effect from a thicker tropospheric clouds providing less longwave heat loss to space, a warming effect from less reflected solar radiation from decreasing low clouds in the tropics and midlatitudes, and a cooling effect from more reflected solar radiation from more low cloud at high latitudes [44]. Hence, the importance and complexity of the carbon-cycle feedbacks, involving partly opposing physical and biogeochemical responses, is comparable to the importance and complexity of the cloud feedbacks in the climate system.

\section{Conclusions}

The climate system is being systematically perturbed by carbon emissions [1, 10], driving rising atmospheric $\mathrm{CO}_{2}$ and surface warming and ocean heat uptake. While there is clearly a warming of the climate system, the amount of carbon that may be emitted before exceeding warming targets is uncertain $[45,46]$. Part of this uncertainty is due to how much of the emitted carbon is sequestered by the land and ocean systems, which may be viewed in terms of a carboncycle response and feedback providing an overall negative feedback to carbon emissions in the climate system.

The carbon-cycle framework provides a methodology to evaluate the carbon-cycle feedbacks, separated into effects due to rising atmospheric $\mathrm{CO}_{2}$ and surface temperature [12-14]. This methodology is very useful by providing an accessible measure of how the carbon cycle operates in a complex climate model. The relative importance of the land and ocean is identified in terms of the carboncycle feedback, although there are inherent approximations through linearising their carbon response relative to the pre-industrial [15]. The usual practice of forcing climate models with prescribed atmospheric $\mathrm{CO}_{2}$ automatically acts to combine the effect of carbon emissions and carbon-cycle feedbacks and possibly under-estimate their combined effect. Instead, there is a greater spread in climate projections when climate models are forced by emissions and there is an interaction with carbon-cycle feedbacks [47].

The carbon-cycle feedback framework by design identifies how the land and ocean carbon inventories depend upon atmospheric $\mathrm{CO}_{2}$ and surface temperature, so ignores the complicating effects of non- $\mathrm{CO}_{2}$ radiative forcing from other greenhouse gases and aerosols. Extending the framework to include the effect of other non- $\mathrm{CO}_{2}$ greenhouse gases, such as methane, and their dependence on surface temperature and atmospheric mixing ratios is possible: there would need to be model integrations with different forcing scenarios and additional differences in coupled model integrations (with components switched on and off) to identify the changes in the surface temperature and atmospheric non$\mathrm{CO}_{2}$ greenhouse gas due to the non- $\mathrm{CO}_{2}$ radiative forcing and the cycling of the non- $\mathrm{CO}_{2}$ greenhouse gases.

While there are underlying approximations, extending the carbon-cycle feedback framework to evaluate a carbon response and feedback parameter $[13,37]$ allows direct comparison with other physical feedback processes contributing to a climate feedback parameter. The carbon and climate responses and feedbacks are directly connected to each other, such as with the carbon response and feedback parameter being proportional to the physical climate feedback parameter. The overall carbon feedback parameter is 
comparable in magnitude to the physical climate feedback parameter and the uncertainty in particular components, particularly the land carbon feedback, are comparable to the uncertainty in the cloud feedback parameter.

Future work should focus on gaining mechanistic insight into those parts of the carbon-cycle feedback that are most significant, which may be achieved by considering further sub-components for the land and ocean carbon system or by considering the regional response of the carbon system. On centennial timescales, the carbon-cycle feedbacks are mainly due to the dependence of the land and ocean carbon inventories on atmospheric $\mathrm{CO}_{2}$ and the dependence of the land carbon inventory to surface warming. However, on longer multi-centennial timescales after carbon emissions cease, the carbon-cycle response is likely to be much more dominated by the ocean rather than the land [48]. Greater mechanistic insight may be achieved by focussing on how physical and biogeochemical processes affect the carbon response for the land and ocean, such as by identifying the carbon responses for the soil and vegetation, and the carbon responses for the ocean saturated, regenerated and disequilibrium pools.

Acknowledgements This work was supported by a U.K. Natural Environment Research Council grant NE/N009789/1. We also acknowledge the World Climate Research Programmes (WRCP) Working Group on Coupled Modelling responsible for CMIP5 that provided access to the outputs from the Earth system models, as well as the organisers of a WRCP Grand Challenge workshop on Carbon Feedbacks in the Climate System in Bern 2018. We thank the Nikki Lovenduski for the invitation to provide this review, and Chris Jones and an anonymous referee for constructive feedback that strengthened the work, and Paulo Ceppi for providing the estimates of physical climate feedbacks.

\section{Compliance with Ethical Standards}

Conflict of Interests On behalf of all authors, the corresponding author states that there is no conflict of interest.

Open Access This article is distributed under the terms of the Creative Commons Attribution 4.0 International License (http:// creativecommons.org/licenses/by/4.0/), which permits unrestricted use, distribution, and reproduction in any medium, provided you give appropriate credit to the original author(s) and the source, provide a link to the Creative Commons license, and indicate if changes were made.

\section{References}

1. Stocker T, Qin D, Plattner GK, Tignor M, Allen S, Boschung J, Nauels A, Xia Y, Bex V, Midgley P, (eds). 2013. Climate change 2013: the physical science basis: Working group I contribution to the Fifth assessment report of the intergovernmental panel on climate change. New York: Cambridge University Press.

2. Stevens B. Water in the atmosphere. Phys Today. 2013;66(6):29.

3. Soden BJ, Held IM. An assessment of climate feedbacks in coupled ocean—atmosphere models. J Climate. 2006;19(14):3354.
4. Zelinka M, Hartmann DL. Climate feedbacks and their implications for poleward energy flux changes in a warming climate. J Climate. 2012;25(2):608.

5. Armour KC, Bitz CM, Roe GH. Time-varying climate sensitivity from regional feedbacks. J Climate. 2013;26:4518.

6. Andrews T, Gregory JM, Webb MJ. The dependence of radiative forcing and feedback on evolving patterns of surface temperature change in climate models. J Climate. 2015;28(4):1630.

7. Ceppi P, Gregory JM. Relationship of tropospheric stability to climate sensitivity and Earth's observed radiation budget. Proc Natl Acad Sci. 2017;114(50):13126.

8. Sherwood SC, Bony S, Boucher O, Bretherton C, Forster PM, Gregory JM, Stevens B. Adjustments in the forcing-feedback framework for understanding climate change. Bull Am Meteorol Soc. 2015;96(2):217.

9. Knutti R, Rugenstein MA. Feedbacks, climate sensitivity and the limits of linear models. Philos Trans R Soc A Math Phys Eng Sci. 2015;373(2054):20150146.

10. Le Quéré C, Andrew RM, Friedlingstein P, Sitch S, Hauck J, Pongratz J, Pickers PA, Korsbakken JI, Peters GP, Canadell JG, et al. Global carbon budget 2018. Earth System Science Data (Online) 10(4):2141-2194. 2018.

11. Friedlingstein P, Dufresne JL, Cox P, Rayner P. How positive is the feedback between climate change and the carbon cycle? Tellus B. 2003;55(2):692.

12. Friedlingstein $\mathrm{P}$, Cox $\mathrm{P}$, Betts R, Bopp L, von Bloh W, Brovkin V, Cadule P, Doney S, Eby M, Fung I, et al. Climatecarbon cycle feedback analysis: results from the C4MIP model intercomparison. J Climate. 2006;19(14):3337.

13. Gregory JM, Jones C, Cadule P, Friedlingstein P. Quantifying carbon cycle feedbacks. J Climate. 2009;22(19):5232.

14. Arora VK, Boera GJ, Friedlingstein P, Eby M, Jones C, Christiana JR, Bonane G, Bopp L, Brovkin V, Cadule P, Hajima T, Ilyina T, Lindsay K, Tjiputra JF, Wu T. Carbon-concentration and carbon-climate feedbacks in CMIP5 Earth System Models. J Climate. 2013. https://doi.org/10.1175/JCLI-D-12-00494.1.

15. Schwinger J, Tjiputra JF, Heinze C, Bopp L, Christian JR, Gehlen M, Ilyina T, Jones C, Salas-Mélia D, Segschneider J, et al. Nonlinearity of ocean carbon cycle feedbacks in CMIP5 Earth system models. J Climate. 2014;27(11):3869.

16. Jones C, Robertson E, Arora V, Friedlingstein P, Shevliakova E, Bopp L, Brovkin V, Hajima T, Kato E, Kawamiya $\mathrm{M}$, et al. Twenty-first-century compatible $\mathrm{CO}_{2}$ emissions and airborne fraction simulated by CMIP5 Earth system models under four representative concentration pathways. J Climate. 2013;26(13):4398.

17. Huntingford C, Cox P. An analogue model to derive additional climate change scenarios from existing GCM simulations. Clim Dyn. 2000;16(8):575.

18. Schwinger J, Tjiputra J. Ocean carbon cycle feedbacks under negative emissions. Geophys Res Lett. 2018;45(10):5062.

19. Goodwin P. On the time evolution of climate sensitivity and future warming. Earth's Future. 2018;6:1336. https://doi.org/10.1029/2018EF000889.

20. Boer G, Arora V. Temperature and concentration feedbacks in the carbon cycle. Geophysical Research Letters 36(2):L02704. https://doi.org/10.1029/2008GL036220. 2009.

21. Arora VK, Scinocca JF, Boer GJ, Christian JR, Denman KL, Flato GM, Kharin VV, Lee WG, Merryfield JW. Carbon emission limits required to satisfy future representative concentration pathways of greenhouse gases. Geophys Res Lett. 2011;38(5):L05805. https://doi.org/10.1029/2010GL046270.

22. Jones C, Hughes JK, Bellouin N, Hardiman SC, Jones GS, Knight J, Liddicoat S, O’Connor FM, Andres RJ, Bell C, Boo KO, Bozzo A, Butchart N, Cadule P, Corbin KD, Doutriaux-Boucher M, Friedlingstein P, Gornall J, Gray L, 
Halloran PR, Hurtt G, Ingram WJ, Lamarque JF, Law RM, Meinshausen M, Osprey S, Palin EJ, Parsons Chini L, Raddatz T, Sanderson MG, Sellar AA, Schurer A, Valdes P, Wood N, Woodward S, Yoshioka M, Zerroukat M. The HadGEM2-ES implementation of CMIP5 centennial simulations. Geosci Model Dev. 2011;4(3):543. https://doi.org/10.5194/gmd-4-543-2011.

23. Dufresne JL, Foujols MA, Denvil S, Caubel A, Marti O, Aumont O, Balkanski Y, Bekki S, Bellenger H, Benshila $\mathrm{R}$, Bony S, Bopp L, Braconnot $\mathrm{P}$, Brockmann $\mathrm{P}$, Cadule $\mathrm{P}$, Cheruy F, Codron F, Cozic A, Cugnet D, de Noblet N, Duvel JP, Ethe C, Fairhead L, Fichefet T, Flavoni S, Friedlingstein P, Grandpeix JY, Guez L, Guilyardi E, Hauglustaine D, Hourdin F, Idelkadi A, Ghattas J, Joussaume S, Kageyama M, Krinner G, Labetoulle S, Lahellec A, Lefebvre MP, Lefevre F, Levy C, Li ZX, Lloyd J, Lott F, Madec G, Mancip M, Marchand M, Masson S, Meurdesoif Y, Mignot J, Musat I, Parouty S, Polcher J, Rio C, Schulz M, Swingedouw D, Szopa S, Talandier C, Terray P, Viovy N, Vuichard N. Climate change projections using the IPSL-CM5 Earth System Model: from CMIP3 to CMIP5. Clim Dyn. 2013;40(9-10):2123. https://doi.org/10.1007/s00382-012-1636-1.

24. Giorgetta MA, Jungclaus J, Reick CH, Legutke S, Bader J, Böttinger M, Brovkin V, Crueger T, Esch M, Fieg K, Glushak K, Gayler V, Haak H, Hollweg HD, Ilyina T, Kinne S, Kornblueh L, Matei D, Mauritsen T, Mikolajewicz U, Mueller W, Notz D, Pithan F, Raddatz T, Rast S, Redler R, Roeckner E, Schmidt H, Schnur R, Segschneider J, Six $\mathrm{KD}$, Stockhause M, Timmreck C, Wegner J, Widmann H, Wieners KH, Claussen M, Marotzke J, Stevens B. Climate and carbon cycle changes from 1850 to 2100 in MPI-ESM simulations for the Coupled Model Intercomparison Project phase 5: Climate Changes in MPI-ESM. J Adv Model Earth Syst. 2013;5(3):572. https://doi.org/10.1002/jame.20038.

25. Tjiputra JF, Roelandt C, Bentsen M, Lawrence DM, Lorentzen T, Schwinger J, Seland O, Heinze C. Evaluation of the carbon cycle components in the Norwegian Earth System Model (NorESM). Geosci Model Dev. 2013;6(2):301. https://doi.org/10.5194/gmd-6-301-2013.

26. Hajima T, Tachiiri K, Ito A, Kawamiya M. Uncertainty of concentration-terrestrial carbon feedback in Earth System Models. J Climate. 2014;27(9):3425.

27. Jones C, Cox P, Huntingford C. Uncertainty in climate-carboncycle projections associated with the sensitivity of soil respiration to temperature. Tellus B. 2003;55(2):642.

28. Cox PM, Pearson D, Booth BB, Friedlingstein P, Huntingford C, Jones C, Luke CM. Sensitivity of tropical carbon to climate change constrained by carbon dioxide variability. Nature. 2013;494(7437):341.

29. Luo Y. Terrestrial carbon-cycle feedback to climate warming. Annu Rev Ecol Evol Syst. 2007;38:683.

30. Pugh T, Jones C, Huntingford C, Burton C, Arneth A, Brovkin V, Ciais P, Lomas M, Robertson E, Piao S, et al. A Large Committed Long-Term Sink of Carbon due to Vegetation Dynamics. Earth's Future. 2018;6(10):1413.

31. Katavouta A, Williams R. The role of ocean physics in controlling the climate response and carbon-cycle feedback to carbon emissions. Journal of Climate, in preparation. 2019.

32. Ito T, Follows MJ. Preformed phosphate, soft tissue pump and atmospheric $\mathrm{CO}_{2}$. J Mar Res. 2005;63:813.

33. Williams R, Follows MJ. Ocean dynamics and the carbon cycle: Principles and mechanisms. Cambridge: Cambridge University Press; 2011.
34. Lauderdale JM, Garabato ACN, Oliver KI, Follows MJ, Williams R. Wind-driven changes in Southern Ocean residual circulation, ocean carbon reservoirs and atmospheric $\mathrm{CO}_{2}$. Clim Dyn. 2013;41(7-8):2145.

35. Bernardello R, Marinov I, Palter JB, Sarmiento JL, Galbraith $\mathrm{ED}$, Slater RD. Response of the ocean natural carbon storage to projected twenty-first-century climate change. J Climate. 2014;27(5):2033.

36. Frank DC, Esper J, Raible CC, Büntgen U, Trouet V, Stocker B, Joos F. Ensemble reconstruction constraints on the global carbon cycle sensitivity to climate. Nature. 2010;463(7280):527.

37. Goodwin P, Williams R, Roussenov V, Katavouta A. Climate sensitivity from both physical and carbon cycle feedbacks. Geophys Res Lett. 46, 7554-7564. 2019. https://doi.org/10.1029/ 2019 GL082887.

38. Gregory JM, Ingram WJ, Palmer MA, Jones GS, Stott PA, Thorpe RB, Lowe JA, Johns TC, Williams KD. A new method for diagnosing radiative forcing and climate sensitivity. Geophys Res Lett. 2004;31:L03205. https://doi.org/10.1029/ 2003 GL018747.

39. Gregory JM, Forster PM. Transient climate response estimated from radiative forcing and observed temperature change. J Geophys Res. 2008;113:D23105.

40. Myhre G, Highwood EJ, Shine KP, Stordal F. New estimates of radiative forcing due to well mixed greenhouse gases. Geophys Res Lett. 1998;25:2715.

41. Forster PM, Andrews T, Good P, Gregory JM, Jackson LS, Zelinka M. Evaluating adjusted forcing and model spread for historical and future scenarios in the CMIP5 generation of climate models. J Geophys Res Atmos. 2013;118(3):1139.

42. Goodwin P, Williams R, Follows MJ, Dutkiewicz S. Oceanatmosphere partitioning of anthropogenic carbon dioxide on centennial timescales. Global Biogeochem Cycl. 2007;21:GB1014.

43. Goodwin P, Follows MJ, Williams R. Analytical relationships between atmospheric carbon dioxide, carbon emissions, and ocean processes. Global Biogeochemical Cycles 22, GB3030. https://doi.org/10.1029/2008GB003184. 2008.

44. Ceppi P, Brient F, Zelinka MD, Hartmann DL. Cloud feedback mechanisms and their representation in global climate models. Wiley Interdiscip Rev Clim Chang. 2017;8(4):e465.

45. Millar RJ, Fuglestvedt JS, Friedlingstein P, Rogelj J, Grubb MJ, Matthews HD, Skeie RB, Forster PM, Frame DJ, Allen MR. Emission budgets and pathways consistent with limiting warming to 1.5 C. Nat Geosci. 2017;10(10):741.

46. Goodwin P, Katavouta A, Roussenov V, Foster GL, Rohling EJ, Williams R. Pathways to $1.5 \mathrm{C}$ and $2 \mathrm{C}$ warming based on observational and geological constraints. Nat Geosci. 2018;11(2):102.

47. Friedlingstein P, Meinshausen M, Arora VK, Jones C, Anav A, Liddicoat SK, Knutti R. Uncertainties in CMIP5 climate projections due to carbon cycle feedbacks. J Climate. 2014;27(2):511.

48. Williams R, Roussenov V, Frölicher TL, Goodwin P. Drivers of continued surface warming after cessation of carbon emissions. Geophys Res Lett. 2017;44(20):10.

Publisher's Note Springer Nature remains neutral with regard to jurisdictional claims in published maps and institutional affiliations. 